\title{
Synthesis and properties of tetrathiafulvalenes bearing 6-aryl-1,4-dithiafulvenes
}

\author{
Aya Yoshimura ${ }^{1,2}$, Hitoshi Kimura ${ }^{1}$, Kohei Kagawa1 ${ }^{1}$, Mayuka Yoshioka ${ }^{1}$, Toshiki Itou ${ }^{1}$, \\ Dhananjayan Vasu ${ }^{3}$, Takashi Shirahata ${ }^{1,2}$, Hideki Yorimitsu ${ }^{3}$ and Yohji Misaki ${ }^{*}{ }^{1,2}$
}

\section{Full Research Paper}

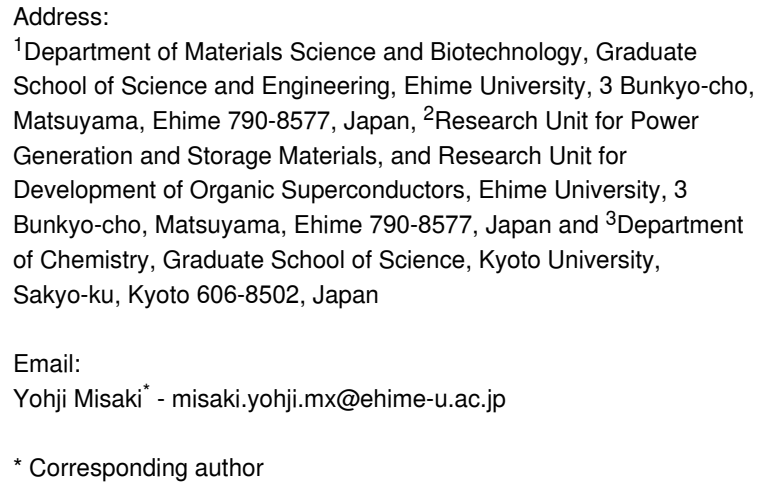

${ }^{1}$ Department of Materials Science and Biotechnology, Graduate School of Science and Engineering, Ehime University, 3 Bunkyo-cho, Matsuyama, Ehime 790-8577, Japan, ${ }^{2}$ Research Unit for Power Generation and Storage Materials, and Research Unit for Development of Organic Superconductors, Ehime University, 3 Bunkyo-cho, Matsuyama, Ehime 790-8577, Japan and ${ }^{3}$ Department of Chemistry, Graduate School of Science, Kyoto University, Sakyo-ku, Kyoto 606-8502, Japan

Email:

Yohji Misaki* - misaki.yohji.mx@ehime-u.ac.jp

* Corresponding author

Keywords:

cross-conjugated systems; electrochemical properties; extended

$\Pi$-conjugation; digital simulation analysis; tetrathiafulvalene
Beilstein J. Org. Chem. 2020, 16, 974-981. doi:10.3762/bjoc. 16.86

Received: 11 February 2020

Accepted: 04 April 2020

Published: 12 May 2020

This article is part of the thematic issue " $\mathrm{C}-\mathrm{H}$ functionalization for materials science".

Guest Editor: K. Itami

(C) 2020 Yoshimura et al.; licensee Beilstein-Institut. License and terms: see end of document.

\begin{abstract}
Novel multistage redox tetrathiafulvalenes (TTFs) bearing 6-aryl-1,4-dithiafulvene moieties were synthesized by palladium-catalyzed direct $\mathrm{C}-\mathrm{H}$ arylation. In the presence of a catalytic amount of $\mathrm{Pd}(\mathrm{OAc})_{2}, \mathrm{P}\left(t-\mathrm{Bu}_{3}\right) \cdot \mathrm{HBF}_{4}$, and an excess of $\mathrm{Cs}_{2} \mathrm{CO}_{3}$, the $\mathrm{C}-\mathrm{H}$ arylation of TTF with several aryl bromides bearing 1,3-dithiol-2-ylidenes took place efficiently to produce the corresponding $\pi$-conjugated molecules. We also succeeded in the estimation of the oxidation potentials and number of electrons involved in each oxidation step of the obtained compounds by digital simulations.
\end{abstract}

\section{Introduction}

Tetrathiafulvalenes (TTFs) with extended $\pi$-conjugation have attracted attention as possible components of functional materials, such as molecular conductors, field-effect transistors (FETs), and positive electrode materials for rechargeable batteries because the TTF moiety has strong electron-donating properties attributed to the formation of stable aromatic 1,3dithiol-2-ylidenes (1,3-dithiole rings) by one- and two-electron oxidation [1-16]. Considerable efforts have been devoted to the development of peripherally benzene- or thiophene-substituted TTFs. As for peripherally benzene-functionalized TTFs, some synthetic approaches, crystal and electronic structures, electrochemical and optical properties, and the nature of radical ion complexes with DDQ or iodine were reported [17-24]. Peripherally thiophene-functionalized TTFs, as potential precursors to 
conducting polymers, and organic metals were also prepared and characterized [25-29]. To design more tempting molecules, the attachment of 1,3-dithiole rings to aromatic rings appears very appealing since these allow to produce novel multistage redox systems. However, such molecules could formerly not be synthesized by conventional approaches. In 2011, a breakthrough synthesis of arylated TTF derivatives by a palladiumcatalyzed direct $\mathrm{C}-\mathrm{H}$ arylation was reported, and the structural and electrochemical properties of the products were clarified [30]. This motivated us to synthesize novel multistage redoxTTFs bearing 1,3-dithiole rings on aromatic rings, 1-3 (Figure 1). In addition, we focused on cross-conjugated systems with 1,3-dithiole rings, which are of interest as novel multistage redox systems as well as donor components for organic conductors [1,31-41]. The palladium-catalyzed $\mathrm{C}-\mathrm{H}$ arylation might offer access to new cross-conjugated molecules bearing vinyl-extended TTF moieties (EBDTs), such as 4 (Figure 1), and the electrochemical properties of these representatives should be brought to light. Herein, we report the synthesis and electrochemical properties of tetrathiafulvalene derivatives 1-4.

\section{Results and Discussion Synthesis}

First, we tried to synthesize compounds $\mathbf{1}$ and $\mathbf{2}$ in one step from pristine TTF and $\mathbf{5}$, respectively, through palladium-catalyzed $\mathrm{C}-\mathrm{H}$ arylation (Table 1 ). When the aryl bromides $\mathbf{6 a}, \mathbf{b}$ were allowed to react with TTF under the conditions A, the products 1a,b were produced in 46 and $48 \%$ yields, respectively (Table 1, entries 1 and 2). Attempted isolations of products 1c and 1d failed, despite complete conversions of TTF, because the polarities of the mono-, di-, and triarylated TTFs were extremely close to that of the tetraarylated TTF 1c and the solubility of these compounds were low and almost beyond isolation for 1d (Table 1, entries 3 and 4). The palladium-catalyzed $\mathbf{C}-\mathrm{H}$ arylation of $\mathbf{5}$ with $\mathbf{6 a}, \mathbf{b}$ proceeded to give products $\mathbf{2 a}, \mathbf{b}$ in 75 and $86 \%$ yields, respectively (Table 1, entries 5 and 6). On the other hand, it was difficult to produce 3 in the same manner because 2-bromothiophenes 7 bearing a 1,3-dithiole ring at the 5-position were unstable, for example, 7a decomposed at around $41-42{ }^{\circ} \mathrm{C}$ (Scheme 1a). Therefore, we achieved the synthesis of $\mathbf{3 a}$ by Pd-catalyzed thienylation of TTF using acetalprotected $\mathbf{8}$, followed by deprotection using PTSA $\cdot \mathrm{H}_{2} \mathrm{O}$ and<smiles>[R]C1=C([R])SC(=Cc2ccc(C3=C(c4ccc(C=C5SC([R])=C([R])S5)cc4)SC(=C4SC(c5ccc(C=C6SC([R])=C([R])S6)cc5)=C(c5ccc(C=C6SC([R])=C([R])S6)cc5)S4)S3)cc2)S1</smiles>

1<smiles>[R]C1=C([R])SC(=Cc2ccc(C3=C(c4ccc(C=C5SC([R])=C([R])S5)s4)SC(=C4SC(c5ccc(C=C6SC([R])=C([R])S6)s5)=C(c5ccc(C=C6SC([R])=C([R])S6)s5)S4)S3)s2)S1</smiles>

3<smiles>[R]C1=C([R])SC(=Cc2ccc(C3=C(c4ccc(C=C5SC([R])=C([R])S5)cc4)SC(=C4Sc5ccccc5S4)S3)cc2)S1</smiles>

2

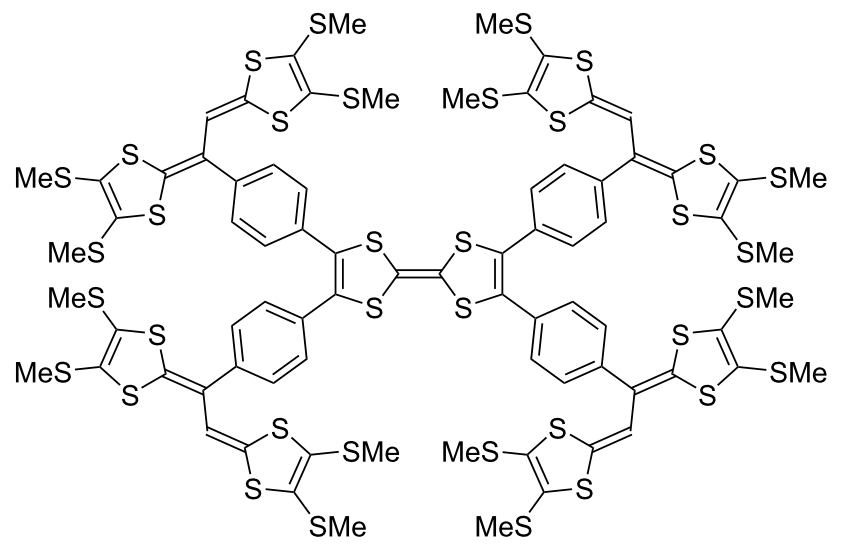

4

Figure 1: Target compounds. 
Table 1: Synthesis of compounds 1 and 2.

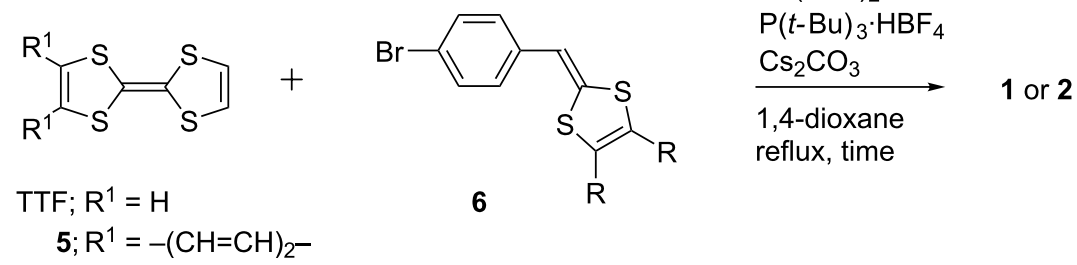

conditions A: $30 \mathrm{~mol} \% \mathrm{Pd}(\mathrm{OAc})_{2}, 90 \mathrm{~mol} \% \mathrm{P}(t-\mathrm{Bu})_{3} \cdot \mathrm{HBF}_{4}, 6$ equiv $\mathrm{Cs}_{2} \mathrm{CO}_{3}, 36 \mathrm{~h}$

B: $60 \mathrm{~mol} \% \mathrm{Pd}(\mathrm{OAc})_{2}, 180 \mathrm{~mol} \% \mathrm{P}(t-\mathrm{Bu})_{3} \cdot \mathrm{HBF}_{4}, 12$ equiv $\mathrm{Cs}_{2} \mathrm{CO}_{3}, 108 \mathrm{~h}$

\begin{tabular}{|c|c|c|c|c|}
\hline entry & TTF or 5 & 6 (equiv) & conditions & yield of 1 or 2 (\%) \\
\hline 1 & TTF & $6 a(5)$ & A & 1a: 46 \\
\hline 2 & TTF & $6 b(5)$ & $A$ & 1b: 48 \\
\hline 3 & TTF & $6 c(5)$ & $A$ or $B$ & 1c: 0 (mixture) \\
\hline 4 & TTF & 6d (5) & $A$ or $B$ & 1d: 0 (mixture) \\
\hline 5 & 5 & $\mathbf{6 a}(2.5)$ & $A^{a}$ & 2a: 75 \\
\hline 6 & 5 & $6 b(2.5)$ & $A^{a}$ & $\mathbf{2 b}: 86$ \\
\hline
\end{tabular}

aReaction time $24 \mathrm{~h}$.

a)<smiles>[R]C1=C([R])SC(=Cc2ccc(Br)s2)S1</smiles>

b)<smiles>C1=CSC(=C2SC=CS2)S1</smiles><smiles>CCOCCc1ccc(Br)s1</smiles>

8

10 equiv
$60 \mathrm{~mol} \% \mathrm{Pd}(\mathrm{OAc})_{2}$ $180 \mathrm{~mol} \% \mathrm{P}(t-\mathrm{Bu})_{3} \cdot \mathrm{HBF}_{4}$ 12 equiv $\mathrm{Cs}_{2} \mathrm{CO}_{3}$

1,4-dioxane, reflux, $72 \mathrm{~h}$<smiles>CCOC(OCC)c1ccc(C2=C(c3ccc(C(OCC)OCC)s3)SC(=C3SC(c4ccc(C(OCC)OCC)s4)=C(c4ccc(C(OCC)c5ccco5)s4)S3)S2)s1</smiles><smiles>Cc1ccc(C2=C(c3ccc(C=O)s3)SC(=C3SC(c4ccc(C=O)s4)=C(c4ccc(C=O)s4)S3)S2)s1</smiles>

10

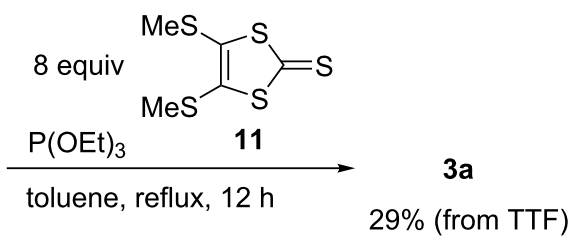

Scheme 1: Synthesis of compounds 3. 
$\mathrm{P}(\mathrm{OEt})_{3}$-mediated cross coupling with 11 (Scheme $1 \mathrm{~b}$ ). The cross-conjugated molecule $\mathbf{4}$ was prepared in two procedures; one was the palladium-catalyzed $\mathrm{C}-\mathrm{H}$ arylation of TTF with bromide 12 (Scheme 2a) and the other was the Vilsmeier-Haack reaction of 1a, followed by triethyl phosphitemediated cross coupling with $\mathbf{1 1}$ (Scheme 2b).

\section{Theoretical calculations}

The DFT calculations of compounds 1a, 3a, and $\mathbf{4}$ have been carried out by using the B3LYP/6-31G(d,p) method [42]. Figure 2 shows an optimized geometry of $\mathbf{1 a}$, and the 1,3dithiole rings are labeled as A-E and A'-E'. This molecule adopted a nonplanar structure. The angle between the two 1,3dithiole rings in the center (A-A') was $158.0^{\circ}$. The dihedral angles between $\mathrm{A}$ and $\mathrm{B}, \mathrm{A}$ and $\mathrm{B}^{\prime}, \mathrm{A}^{\prime}$ and $\mathrm{C}$, and $\mathrm{A}^{\prime}$ and $\mathrm{C}^{\prime}$ were $49.8^{\circ}, 137.7^{\circ}, 137.7^{\circ}$, and $49.9^{\circ}$, respectively. The HOMO, HOMO-1, and LUMO of 1a are shown in Figure 3. The HOMO of 1a was mainly located on the TTF moiety, whereas the HOMO-1 was located on the benzene ring and the outer 1,3-dithiole rings at the peripheral part of TTF. The LUMO of 1a spread over the whole molecule except the outer 1,3-dithiole rings. The orbital energy of the HOMO of $\mathbf{1 a}$ $(-4.41 \mathrm{eV})$ was slightly higher than that of TTF $(-4.57 \mathrm{eV})$. As such, the first oxidation of 1a might occur at a lower potential than TTF [43].

\section{Cyclic voltammetry analysis}

The redox behavior of 1-4 was investigated by cyclic voltammetry. The compounds $\mathbf{1 a}$ and $\mathbf{1 b}$ exhibited four and three pairs of redox waves, respectively (around $+0.03,+0.10,+0.17$, and $+0.42 \mathrm{~V}$ vs $\mathrm{Fc} / \mathrm{Fc}^{+}$for $1 \mathrm{a}$ and $-0.05,+0.10$, and $+0.46 \mathrm{~V}$ vs $\mathrm{Fc} / \mathrm{Fc}^{+}$for $\mathbf{1 b}$, Figure 4 ). The redox potentials of $\mathbf{1 a}, \mathbf{b}$ are summarized in Table 2 together with the related compound TTF. The redox waves observed at $+0.42 \mathrm{~V}$ for $1 \mathrm{a}$ and $+0.46 \mathrm{~V}$ for 1b were likely related to the second redox of the central TTF moiety because they were close to the $E_{2}$ of TTF $(+0.37 \mathrm{~V})$. The remaining redox processes observed at around +0.03 , +0.10 , and $+0.17 \mathrm{~V}$ for $\mathbf{1 a}$, and -0.05 and $+0.10 \mathrm{~V}$ for $\mathbf{1 b}$ might have been derived from the first redox of the central TTF moiety and the redox of the four outer 1,3-dithiole rings. To elaborate the exact oxidation potentials and the number of electrons involved in each oxidation step, a digital simulation technique was applied [44]. As a result, the observed redox waves of 1a matched the simulated waves (Table 2). It was indicated that the redox wave at $+0.10 \mathrm{~V}$ was due to an overlap of the sequential two stages of the one- and two-electron transfer waves at +0.07 and $+0.12 \mathrm{~V}$, while the other waves corresponded to one-electron transfer processes. The simulation results of 1a also showed that the redox wave simulated at $+0.020 \mathrm{~V}$ might have been derived from the central TTF moiety because of the close $\Delta E$ values $(+0.40 \mathrm{~V}$ for $1 \mathrm{a}$ and $+0.46 \mathrm{~V}$ for TTF). The same discussion was applied to $\mathbf{1 b}$. In addition, the potentials related to the outer 1,3-dithiole rings of $\mathbf{1 a}, \mathbf{b}$ were influenced by the substituents, that is, $\mathbf{1 b}$ bearing electron-donating methyl groups had more negative redox potentials than 1a. As a consequence, the one-electron redox process of the TTF moiety and the multi-electron redox processes of the outer 1,3-dithiole rings might have overlapped in $\mathbf{1 b}$.<smiles>CC(=O)C1=C(C)SC(=CC(=C2SC(C)=C(S(C)(=O)=O)S2)c2ccc(Br)cc2)S1</smiles>

b)

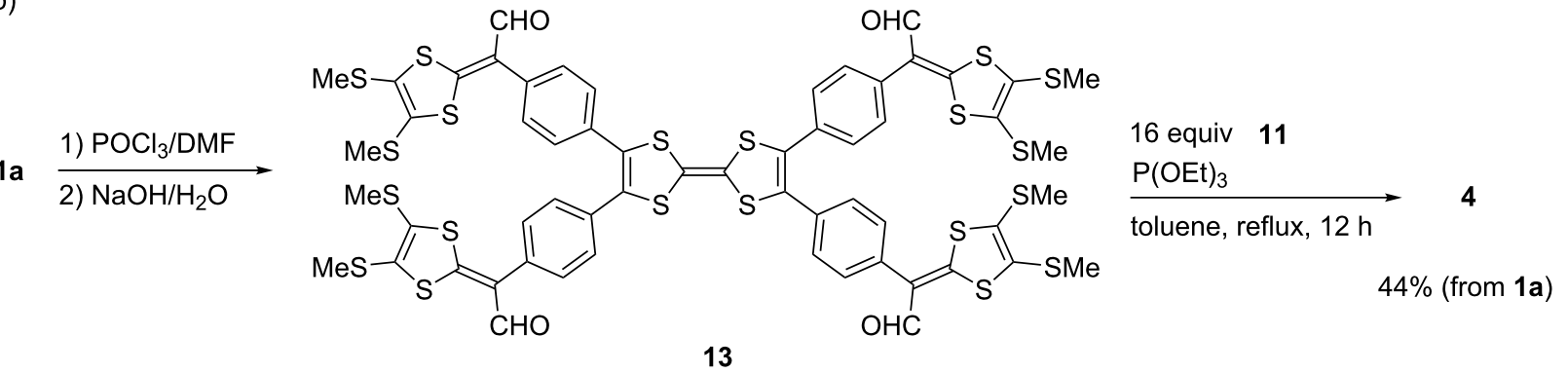


a)

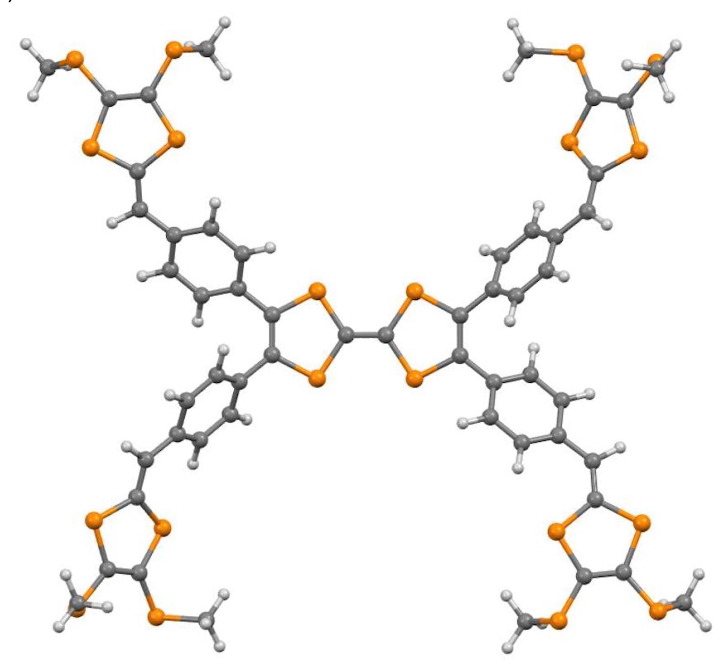

b)

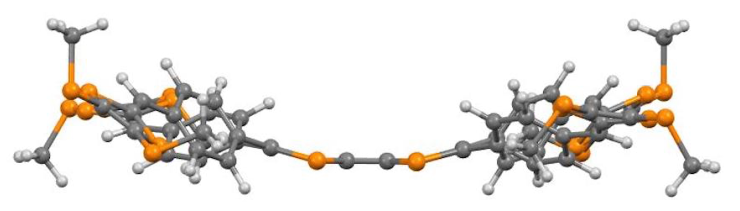

c)

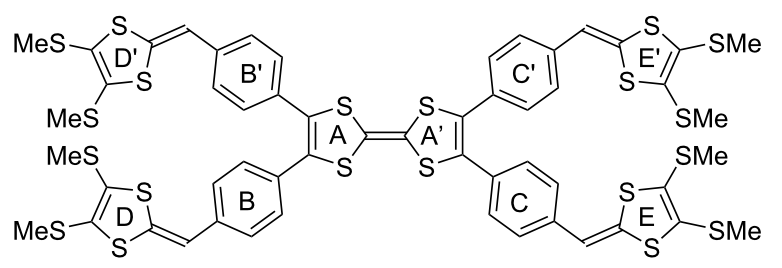

Figure 2: An optimized structure of 1a. a) Top view, b) side view, and c) labeling of the 1,3-dithiole rings.

Compound 2a exhibited three pairs of redox waves $(-0.05$, +0.09 , and $+0.49 \mathrm{~V}$ vs $\left.\mathrm{Fc} / \mathrm{Fc}^{+}\right)$. The redox waves observed at -0.05 and $+0.49 \mathrm{~V}$ were likely related to the TTF derivative (5) moiety, because they were close to the $E_{1}$ and $E_{2}$ of $\mathbf{5}$, respectively (Table 2). The comparison of the peak currents of each wave indicated that the redox wave observed at $+0.09 \mathrm{~V}$ involved a two-electron transfer, while the redox waves observed at -0.05 and $+0.49 \mathrm{~V}$ corresponded to one-electron transfer processes (see the differential pulse voltammetry (DPV) in Supporting Information File 1, Figure S2). These results supported the above-mentioned oxidation potentials and the number of electrons involved in each oxidation step of $\mathbf{1 a}, \mathbf{b}$

Compound 4 exhibited three pairs of redox waves (around $-0.09,+0.09$, and $+0.53 \mathrm{~V}$ vs $\left.\mathrm{Fc} / \mathrm{Fc}^{+}\right)$. The redox potentials of $\mathbf{4}$
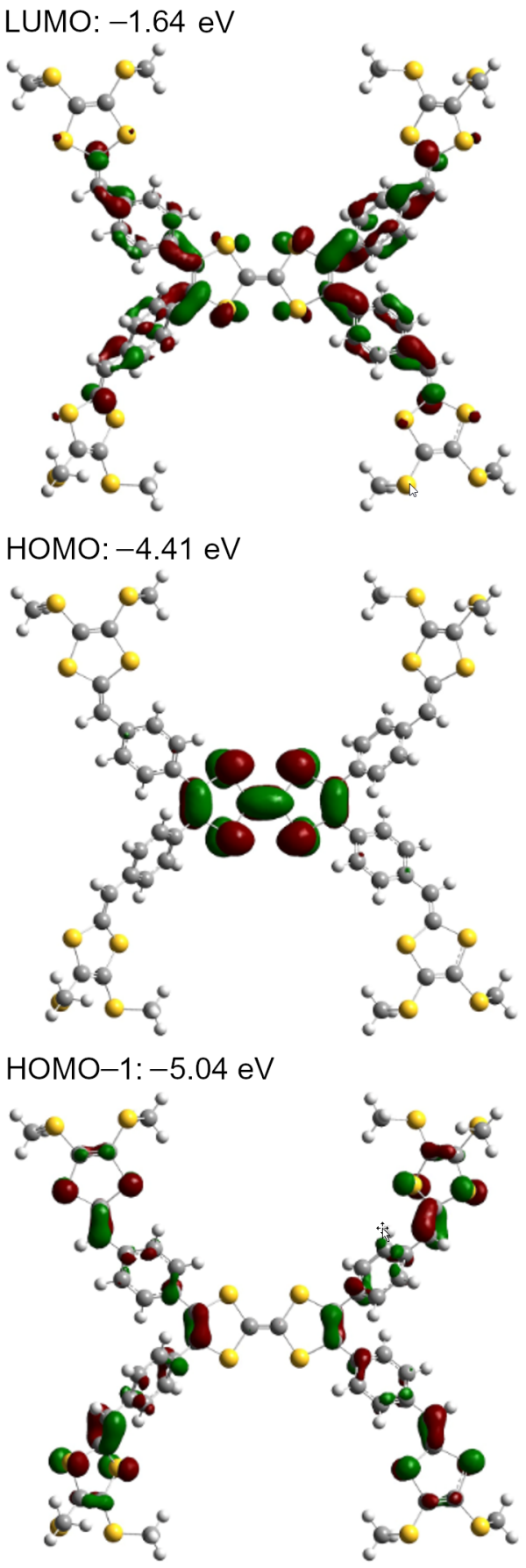

Figure 3: Molecular orbitals of 1a.

and the simulation results are also summarized in Table 2, together with those of the related compounds TTF and $\mathbf{1 4}$ (see Figure 5). The redox process observed at $+0.53 \mathrm{~V}$ was likely related to the second redox of the central TTF moiety because this was the closest to the value of the $E_{2}$ of TTF $(+0.37 \mathrm{~V})$ out of all potentials of the related compounds TTF and 14. The 

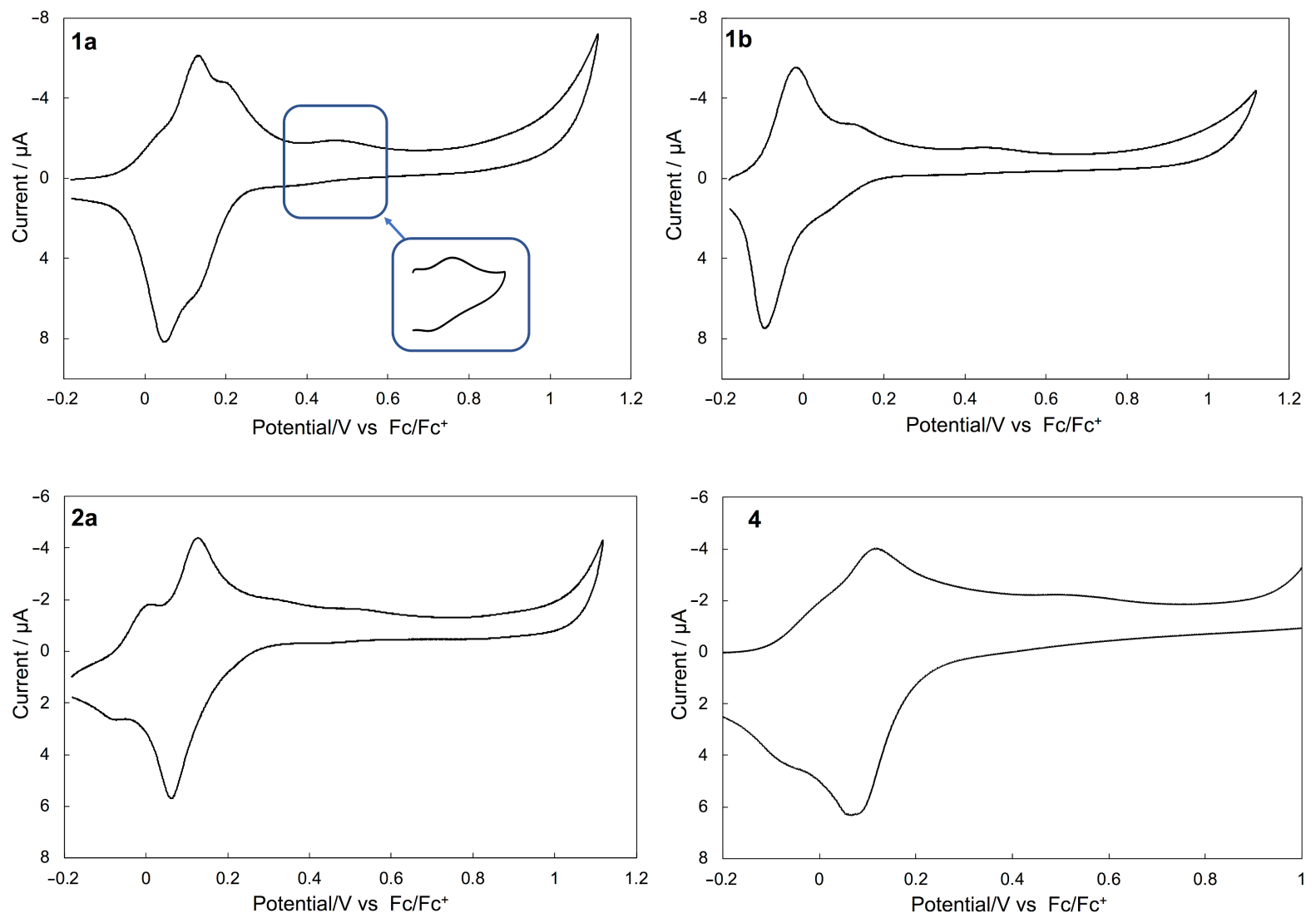

Figure 4: Cyclic voltammograms of 1a,b, 2a, and 4 in ${\mathrm{PhCN} / \mathrm{CS}_{2}}_{2}$ :1 (v/v) solution.

Table 2: Redox potentials of $\mathbf{1}, \mathbf{2 a}, \mathbf{4}$, and related compounds ${ }^{\mathrm{a}}$.

\begin{tabular}{|c|c|c|c|c|c|c|c|c|c|c|c|}
\hline compound & $\begin{array}{l}\text { observed or } \\
\text { simulated value }\end{array}$ & $E_{1}$ & $E_{2}$ & $E_{3}$ & $E_{4}$ & $E_{5}$ & $E_{6}$ & $E_{7}$ & $E_{8}$ & $E_{9}$ & $E_{10}$ \\
\hline \multirow[t]{2}{*}{$1 a$} & observed & $\begin{array}{l}\text { around } \\
+0.03^{b}\end{array}$ & +0.10 & & & +0.17 & +0.42 & & & & \\
\hline & simulated & +0.020 & +0.070 & +0.120 & & +0.200 & +0.420 & & & & \\
\hline $1 b$ & observed & -0.05 & & & & +0.10 & $+0.46^{\mathrm{b}}$ & & & & \\
\hline $2 a$ & observed & -0.05 & +0.09 & & +0.49 & & & & & & \\
\hline \multirow[t]{2}{*}{4} & observed & around & -0.09 & & +0.09 & & & & & & $+0.53^{b}$ \\
\hline & simulated & -0.060 & -0.030 & +0.010 & +0.047 & +0.053 & +0.098 & +0.102 & +0.110 & +0.180 & +0.500 \\
\hline TTF $^{\mathrm{C}}$ & observed & -0.09 & +0.37 & & & & & & & & \\
\hline $5^{c}$ & observed & -0.01 & +0.42 & & & & & & & & \\
\hline $14^{\mathrm{C}}$ & observed & -0.07 & +0.09 & & & & & & & & \\
\hline
\end{tabular}

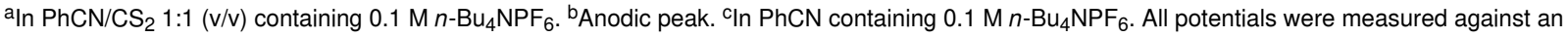
$\mathrm{Ag} / \mathrm{Ag}^{+}$reference electrode and converted to vs $\mathrm{Fc} / \mathrm{Fc}^{+}$.

remaining redox processes observed at around -0.09 and $+0.09 \mathrm{~V}$ might have been due to the first redox of the central TTF moiety, and the overall redox of the EBDT sites, respec- tively. The observed potentials of $\mathbf{4}$ were generally consistent with the simulated ones. The results of a digital simulation also showed that the redox wave observed at around $-0.09 \mathrm{~V}$ and 
$+0.09 \mathrm{~V}$ corresponded to three stages of one-electron transfer and six stages of one-electron transfer processes, respectively. In addition to the overlap of the first redox of the central TTF moiety and the redox of the EBDT sites, each redox potential of the succeeding eight-electron oxidations of the EBDT sites might have slightly shifted due to the non-equivalence of them. Also, the small $\Delta E$ value $(0.16 \mathrm{~V})$ of $\mathbf{1 4}$ caused the redox wave overlap. For these reasons, the first and second redox waves of $\mathbf{4}$ were broad compared to those of $\mathbf{1 a}$ and $\mathbf{1 b}$.

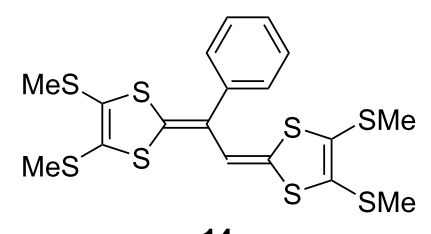

14

Figure 5: Related compound 14

The redox waves of $\mathbf{1 a}, \mathbf{b}$ and $\mathbf{4}$ derived from the second redox of the central TTF moiety $(+0.42 \mathrm{~V}$ for $\mathbf{1 a},+0.46 \mathrm{~V}$ for $\mathbf{1 b}$, and $+0.53 \mathrm{~V}$ for 4 ) shifted to higher potentials than the second redox of TTF because of the instability of the hexacationic state of $\mathbf{1 a}, \mathbf{b}$, and the decacationic state of $\mathbf{4}$ compared to the dicationic states of TTF caused by on-site Coulomb repulsion between positive charges in the central TTF moiety and the outer 1,3dithiole rings. The same discussion could be applied to compounds 2a. In addition, the observed peak currents of $\mathbf{1 a}$ and $\mathbf{4}$ in the high potential region at +0.4 to $+0.5 \mathrm{~V}$ were smaller than those of the simulated waves. This phenomenon might be understood by considering that electron transfer of this redox reaction was slow enough to become the rate-determining step because the crowded structure by which the TTF core is participating in this redox process is surrounded by extended aromatic rings bearing 1,3-dithiol rings.

\section{Conclusion}

We have synthesized novel multistage TTF derivatives 1-4 bearing 6-aryl-1,4-dithiafulvene moieties by palladium-catalyzed direct $\mathrm{C}-\mathrm{H}$ arylation. The DFT calculations revealed the nonplanar structure of the compounds. Cyclic voltammograms of $\mathbf{1 a}$ and $\mathbf{4}$ comprised four and three pairs of redox waves, respectively. As a result of the digital simulation of 1a, it was shown that the redox wave observed at $+0.10 \mathrm{~V}$ involved two stages of one- and two-electron transfer(s), while the other redox waves corresponded to one-electron transfer. The digital simulation of $\mathbf{4}$ showed 10 stages of one-electron transfer in total. In addition, the first and second redox waves of $\mathbf{4}$ were broad compared to those of $\mathbf{1}$ owing to the following three reasons: a) overlap of the central TTF moiety and the redox of the EBDT sites, b) the succeeding eight-electron oxidations of the non-equivalent EBDT sites, and c) the small $\Delta E$ value $(0.16 \mathrm{~V})$ of the EBDT sites.

\section{Supporting Information}

\section{Supporting Information File 1}

Synthetic procedures, theoretical chemical and electrochemical details, and copies of NMR spectra. [https://www.beilstein-journals.org/bjoc/content/ supplementary/1860-5397-16-86-S1.pdf]

\section{Funding}

This work was partially supported by a Grant-in-Aid for Scientific Research (JP15H03798), from the Ministry of Education, Culture, Sports, Science and Technology (MEXT). This work was also supported by a Grant-in-Aid for Research Promotion, Ehime University, to The Research Unit for Development of Organic Superconductors and to The Research Unit for Power Generation and Storage Materials.

\section{ORCID ${ }^{\circledR}$ iDs}

Aya Yoshimura - https://orcid.org/0000-0001-9967-4598 Dhananjayan Vasu - https://orcid.org/0000-0001-7597-3710 Takashi Shirahata - https://orcid.org/0000-0003-0899-3767 Hideki Yorimitsu - https://orcid.org/0000-0002-0153-1888 Yohji Misaki - https://orcid.org/0000-0002-9079-8487

\section{Preprint}

A non-peer-reviewed version of this article has been previously published as a preprint doi:10.3762/bxiv.2020.16.v1

\section{References}

1. Yamada, J.; Sugimoto, T., Eds. TTF Chemistry-Fundamental and Applications of Tetrathiafulvalene; Kodansha-Springer: Tokyo, 2004.

2. Canevet, D.; Sallé, M.; Zhang, G.; Zhang, D.; Zhu, D. Chem. Commun. 2009, 2245-2269. doi:10.1039/b818607n

3. Gorgues, A.; Hudhomme, P.; Sallé, M. Chem. Rev. 2004, 104, 5151-5184. doi:10.1021/cr0306485

4. Segura, J. L.; Martín, N. Angew. Chem., Int. Ed. 2001, 40, 1372-1409. doi:10.1002/1521-3773(20010417)40:8<1372::aid-anie1372>3.0.co;2-i

5. lyoda, M.; Hasegawa, M.; Miyake, Y. Chem. Rev. 2004, 104, 5085-5114. doi:10.1021/cr0306510

6. Hasegawa, M.; Iyoda, M. Tetrathiafulvalene: A Redox Unit for Functional Materials and a Building Block for Supramolecular Self-Assembly. In Organic Redox Systems; Nishinaga, T., Ed.; John Wiley \& Sons: Hoboken, NJ, USA, 2015; pp 89-129. doi:10.1002/9781118858981.ch4

7. Misaki, Y. Sci. Technol. Adv. Mater. 2009, 10, 024301. doi:10.1088/1468-6996/10/2/024301 
8. Inatomi, Y.; Hojo, N.; Yamamoto, T.; Shimada, M.; Watanabe, S. Examination of Multi-Electron Reaction Type pi-Conjugated Organic Compounds as Cathode Active Material for Rechargeable Power Supply. In ECS Meeting Abstracts, Volume MA2008-01, B1-Batteries General Session, Abstract \#167, 213th ECS meeting, Phoenix, Arizona, May 18-22, 2008; The Electrochemical Society, 2008. doi:10.1149/ma2008-01/5/167

9. Inatomi, Y.; Hojo, N.; Yamamoto, T.; Watanabe, S.-i.; Misaki, Y. ChemPlusChem 2012, 77, 973-976. doi:10.1002/cplu.201200197

10. Kato, M.; Ogi, D.; Yao, M.; Misaki, Y. Chem. Lett. 2013, 42, 1556-1558. doi:10.1246/cl.130841

11. Kato, M.; Senoo, K.-i.; Yao, M.; Misaki, Y. J. Mater. Chem. A 2014, 2 , 6747-6754. doi:10.1039/c3ta14920j

12. Iwamoto, S.; Inatomi, Y.; Ogi, D.; Shibayama, S.; Murakami, Y.; Kato, M.; Takahashi, K.; Tanaka, K.; Hojo, N.; Misaki, Y. Beilstein J. Org. Chem. 2015, 11, 1136-1147. doi:10.3762/bjoc.11.128

13. Yamauchi, T.; Shibata, Y.; Aki, T.; Yoshimura, A.; Yao, M.; Misaki, Y. Chem. Lett. 2018, 47, 1176-1179. doi:10.1246/cl.180496

14. Ogi, D.; Fujita, Y.; Kato, M.; Yamauchi, T.; Shirahata, T.; Yao, M.; Misaki, Y. Eur. J. Org. Chem. 2019, 2725-2728. doi:10.1002/ejoc.201801877

15. Yamauchi, T.; Kato, M.; Shirahata, T.; Yao, M.; Misaki, Y. Chem. Lett. 2019, 48, 1507-1510. doi:10.1246/cl.190703

16. Bryce, M. R. J. Mater. Chem. 2000, 10, 589-598. doi:10.1039/a908385e

17. Coffen, D. L.; Chambers, J. Q.; Williams, D. R.; Garrett, P. E.; Canfield, N. D. J. Am. Chem. Soc. 1971, 93, 2258-2268. doi:10.1021/ja00738a028

18. Ueno, Y.; Okawara, M. Chem. Lett. 1974, 3, 1135-1138. doi:10.1246/cl.1974.1135

19. Ueno, Y.; Nakayama, A.; Okawara, M. J. Am. Chem. Soc. 1976, 98 , 7440-7441. doi:10.1021/ja00439a064

20. Yoneda, S.; Kawase, T.; Inaba, M.; Yoshida, Z.-i. J. Org. Chem. 1978, 43, 595-598. doi:10.1021/jo00398a015

21. Le Coustumer, G.; Mollier, Y. J. Chem. Soc., Chem. Commun. 1980 , 38-39. doi:10.1039/c39800000038

22. Babeau, A.; Tinh, N. H.; Gasparoux, H.; Polycarpe, C.; Torreilles, E.; Giral, L. Mol. Cryst. Liq. Cryst. 1982, 72, 171-176. doi:10.1080/01406568208084054

23. Starodub, V. A.; Baumer, V. N.; Guella, I. M.; Golovkina, I. F.; Alyoshin, V. G.; Nemoshkalenko, V. V.; Senkiewicz, A. I. Synth. Met. 1983, 5, 101-111. doi:10.1016/0379-6779(83)90124-8

24. Tsujimoto, K.; Okeda, Y.; Ohashi, M. J. Chem. Soc., Chem. Commun. 1985, 1803-1804. doi:10.1039/c39850001803

25. Charlton, A.; Underhill, A. E.; Williams, G.; Kalaji, M.; Murphy, P. J.; Hibbs, D. E.; Hursthouse, M. B.; Malik, K. M. A. Chem. Commun. 1996, 2423-2424. doi:10.1039/cc9960002423

26. Charlton, A.; Underhill, A. E.; Williams, G.; Kalaji, M.; Murphy, P. J.; Malik, K. M. A.; Hursthouse, M. B. J. Org. Chem. 1997, 62, 3098-3102. doi:10.1021/j0962301q

27. Gompper, R.; Hock, J. Synth. Met. 1997, 84, 339-340. doi:10.1016/s0379-6779(97)80771-0

28. Zotti, G.; Zecchin, S.; Schiavon, G.; Berlin, A.; Huchet, L.; Roncali, J. J. Electroanal. Chem. 2001, 504, 64-70. doi:10.1016/s0022-0728(01)00429-6

29. Kakinuma, T.; Kojima, H.; Kawamoto, T.; Mori, T. J. Mater. Chem. C 2013, 1, 2900-2905. doi:10.1039/c3tc30089g

30. Mitamura, Y.; Yorimitsu, H.; Oshima, K.; Osuka, A. Chem. Sci. 2011, 2, 2017-2021. doi:10.1039/c1sc00372k
31. Gholami, M.; Tykwinski, R. R. Chem. Rev. 2006, 106, 4997-5027. doi:10.1021/cr0505573

32. Sugimoto, T.; Awaji, H.; Misaki, Y.; Yoshida, Z.-i.; Kai, Y.; Nakagawa, H.; Kasai, N. J. Am. Chem. Soc. 1985, 107, 5792-5793. doi:10.1021/ja00306a030

33. Sugimoto, T.; Misaki, Y.; Arai, Y.; Yamamoto, Y.; Yoshida, Z.-i.; Kai, Y.; Kasai, N. J. Am. Chem. Soc. 1988, 110, 628-629. doi:10.1021/ja00210a069

34. Misaki, Y.; Matsumura, Y.; Sugimoto, T.; Yoshida, Z.-i. Tetrahedron Lett. 1989, 30, 5289-5292. doi:10.1016/s0040-4039(01)93767-0

35. Amaresh, R. R.; Liu, D.; Konovalova, T.; Lakshmikantham, M. V.; Cava, M. P.; Kispert, L. D. J. Org. Chem. 2001, 66, 7757-7764. doi:10.1021/jo010663e

36. Rajagopal, D.; Lakshmikantham, M. V.; Cava, M. P. Org. Lett. 2002, 4, 2581-2583. doi:10.1021/ol026227b

37. Coffin, M. A.; Bryce, M. R.; Batsanov, A. S.; Howard, J. A. K. J. Chem. Soc., Chem. Commun. 1993, 552-554. doi:10.1039/c39930000552

38. Bryce, M. R.; Coffin, M. A.; Skabara, P. J.; Moore, A. J.; Batsanov, A. S.; Howard, J. A. K. Chem. - Eur. J. 2000, 6, 1955-1962. doi:10.1002/1521-3765(20000602)6:11<1955::aid-chem1955>3.0.co;2b

39. Hasegawa, M.; Fujioka, A.; Kubo, T.; Honda, T.; Miyamoto, H.; Misaki, Y. Chem. Lett. 2008, 37, 474-475. doi:10.1246/cl.2008.474

40. Horiuchi, H.; Misaki, Y. Chem. Lett. 2010, 39, 989-991. doi:10.1246/cl.2010.989

41. Nishiwaki, M.; Tezuka, M.; Shirahata, T.; Misaki, Y. Chem. Lett. 2011, 40, 467-469. doi:10.1246/cl.2011.467

42. Gaussian 16, Revision C.01; Gaussian, Inc.: Wallingford, CT, 2019.

43. The optimized geometries and energy levels of the LUMO, HOMO, and HOMO-1 of $\mathbf{3 a}$ and $\mathbf{4}$ are shown in Supporting Information File 1, Figure $\mathrm{S} 1$.

44. DigiElch 7 Prof software; Elchsoft: Kleinromstedt, Germany.

\section{License and Terms}

This is an Open Access article under the terms of the Creative Commons Attribution License (http://creativecommons.org/licenses/by/4.0). Please note that the reuse, redistribution and reproduction in particular requires that the authors and source are credited.

The license is subject to the Beilstein Journal of Organic Chemistry terms and conditions: (https://www.beilstein-journals.org/bjoc)

The definitive version of this article is the electronic one which can be found at: doi: $10.3762 /$ bjoc. 16.86 